\title{
Cultural Influences on Consumer Behaviour
}

\author{
Tahmid Nayeem ${ }^{1}$ \\ ${ }^{1}$ Swinburne University of Technology, Australia \\ Correspondence: Dr Tahmid Nayeem, Swinburne University of Technology, Australia. E-mail: \\ tnayeem@swin.edu.au
}

Received: August 23, 2012 Accepted: September 7, 2012 Online Published: October 18, 2012

doi:10.5539/ijbm.v7n21p78 URL: http://dx.doi.org/10.5539/ijbm.v7n21p78

\begin{abstract}
This study investigates the differences between individualism-collectivism and consumer behaviour in relation to automobile purchases. In this study the author looked at several stages of the consumer decision-making process and identified the possible differences between individualist and collectivist consumers and how it influences purchase decision. Based on a sample of 211 respondents from individualist (Australian-born) and collectivist (Asian-born) backgrounds, an established scale (Cultural Values Scale: Singelis, Triandis, Bhawuk, \& Gelfand, 1995) was used to confirm the cultural values among the participants, if the respondents are aligned with the particular group (i.e. Asian-born with collectivism and Australian-born with individualism). Hypotheses were tested using independent sample t-test. Results found that there were no differences in individualism observed between Australian-born and Asian-born respondents; however, there were differences in collectivism observed between these two groups, such that Asian-born participants scored higher on collectivism. Results also found that Asian-born consumers are more brand conscious and involve a number of family/friends in their decision making. In contrast Australian-born consumers do not believe in group decision making and uses internet as the most important source of information. The findings will provide insight into how automobile companies could position themselves with respect to their marketing strategies in different cultural settings.
\end{abstract}

Keywords: cultural values, consumer decision-making process, automobile purchases

\section{Introduction}

Culture is a powerful force in regulating human behaviour. It consists of a common set of behaviour patterns that are transmitted and maintained by the members of a particular society through various means (Arnolds \& Thompson, 2005). For example, members within the same culture have similarities of language (Lee, 2000), pattern instruction (Kelley \& Wendt, 2002) and imitation (Barney, 1986), and they share the same values (Hofstede, 2001). These values are likely to affect consumer behaviour and set the choice of criteria used by individual consumers.

Cultural values are the vehicles which carry culturally-determined knowledge from one generation to another; that is, they are the form in which culture is stored and expressed (Mourali, Laroche, \& Pons, 2005). These values are socialised into a particular group and are passed on to the next generation (Triandis, 1995). As a result, values persist over time and, therefore, may have an influence on the way consumers behave. This further influences the choices that individuals make regarding consumer decisions from everyday products to major or important purchases (Luna \& Gupta, 2001).

There is hardly any aspect of life that cultural values do not affect (Mourali et al., 2005). The cultural value system includes cultural elements that people have in common with the group to which they belong, as well as idiosyncratic values unique to that individual (Luna \& Gupta, 2001). Societal culture, as well as regional subculture and familial values, all influence the formation of an individual's cultural values. Thus, from the beginning of an individual's existence, he/she experiences the benefits and restrictions of a particular culture, and those benefits and restrictions may become a major influence upon consumers' purchasing decisions (de Mooij, 2010). For example, some cultures have a general trait of caution towards new experiences. Consumers from these cultural backgrounds are more likely to rely on traditional values (Manrai, Lascu, Manrai, \& Babb, 2001), which means, first of all, that they learn through observation rather than immediately purchasing new or innovative products. This approach creates limitations in terms of product preferences or choices (Leo, Bennett, 
\& Hartel, 2005). Cultural value differences among consumers may cause difficulties for researchers in understanding consumer behaviour in a multicultural environment.

However, culture is generally accepted by marketing researchers as one of the most important underlying determinants of consumer behaviour (de Mooij, 2010). Marketing researchers have previously used cultural dimensions, for example, individualism-collectivism, to measure the impact of cultural values in consumer behaviour research (see Luna \& Gupta, 2001). Previous studies include cultural differences in consumer complaint behaviour (Liu \& McClure, 2001), consumer innovativeness (Steenkamp, 2001), consumer retailing (de Mooij \& Hofstede, 2002) and impulse buying (Kacen \& Lee, 2002). The use of individualism-collectivism for measuring cultural values is, therefore, a key concept that has been successfully used in cross-cultural marketing research (Bond et al., 2004).

With so much emphasis on individualism-collectivism in cross-cultural marketing research, it is surprising to note that there is very little information regarding the influence of individualism-collectivism when buying high involvement products (Luna \& Gupta, 2001). In more general terms, research has shown that culture may act as an intention inhibitor in relation to high involvement purchases (Henry, 1976). Therefore, it may be reasonable to assume that commonly held individualism-collectivism values can shape (to some extent) the choice of what is or is not valued among specific products. These values may lead to different product choices being made by individuals within these two cultural groups of individualism and collectivism (Doran, 2002). If this relationship between individualism-collectivism and high involvement purchases can be demonstrated, then culture can become an even more useful and valuable marketing tool (Manrai \& Manrai, 1996; Jung \& Sung, 2008). This study aims to achieve this by investigating individualist and collectivist consumers' values which influence their purchase behaviour. In this study the author has looked at in several stages of consumer decision-making process in relation to automobile purchases, which may help marketing practitioners to communicate with potential and current consumers within these cultural groups.

\section{The Effect of Individualism-Collectivism on Consumer Behaviour}

Hofstede's work (1980, 1983, 1984, \& 2001) has established that the United States, Australia, the United Kingdom (UK) and other Western countries cluster toward the individualist end of the continuum, whilst India, Pakistan, Thailand, Hong Kong, China and other Asian countries cluster toward the collectivist end (Hofstede, 2001). According to Hofstede (2001), every national population shares a national culture. 'National culture' is the only culture within a nation, culturally distinguishing the population of one nation from the population of another. McSweeney (2002) critiqued Hofstede's model of national cultural differences, arguing that assumption of equating nation with culture provided a limited representation of culture. McSweeney suggested that alternative conceptions of culture should consider multiple, non-national influencing factors. Perhaps the most significant alternative view to Hofstede's national culture to have emerged is the view that cultural dimensions such as individualism and collectivism operate in all societies, and individualistic and collectivistic tendencies can be found within any given culture at different levels (Triandis, 1995). While Hofstede's view suggests that Eastern cultures are collectivistic and Western cultures are individualistic, the alternative view suggests that Easterners and Westerners do not necessarily differ from one another on these dimensions.

However, the interaction between individualism-collectivism and consumer behaviour is an exciting phenomenon for cross-cultural consumer behaviour researchers to observe (Leo et al., 2005). Cross-cultural researchers have recognised culture as one of the most influential determinants of consumer behaviour (Cleveland \& Chang, 2009). Consumers' cultural background not only shapes their needs and wants, but also influences the way marketing strategies are developed to target market behaviours, attitudes and preferences (Venkatesh, 1995). This influence is displayed in the variation in strategies marketers use when targeting buyers in different cultural contexts. For example, in collectivist societies, the focus of advertising is upon status, symbolism, prestige and also on family or in-group benefits (de Mooij, 2004). However, in individualist societies the focus is on features such as design and performance (Farhangmehr \& Shoham, 2006). Individualist consumers are more interested in knowing about the capabilities of the product before they purchase, as opposed to collectivists who rely a great deal on other factors for decision-making such as status and symbolism (Dhar, 2007). However, the way in which these factors influence consumers' purchasing decisions in individualist and collectivist cultures has not been extensively studied (Latvin \& Kar, 2007). Therefore, in order to effectively communicate with consumers in these cultural groups, research focusing on the connection between culture and consumer behaviour is needed (Luna \& Gupta, 2001).

Previous studies indicated that individualism-collectivism is likely to affect consumer behaviour and, as such, marketing communication messages need to be developed on the basis of these effects. This means the 
communication techniques selected could differ according to cultural background (Luna \& Gupta, 2001). As discussed above, in terms of decision-making, collectivist consumers are likely to focus on family and in-group benefits. On the other hand, individualist consumers are likely give priority to personal benefits over communal benefits or interests. In terms of decision-making, collectivist consumers are likely to rely a great deal on external information sources, such as family and friends, whilst individualist consumers base decisions upon information gathered through personal experiences (Doran, 2002). Therefore, it is important to identify which types of information sources are more preferable for targeting individualist and collectivist consumers. Previous studies have not examined the importance of information sources in consumer decision-making (Luna \& Gupta, 2001), such as what type of information sources individualist and collectivist consumers prefer when they are making high involvement purchases like automobiles. Research into this area could help to provide an understanding of how to best communicate within the cultural dimensions of individualism and collectivism.

Since cultural dimensions such as individualism-collectivism are a major determinant of a variety of attitudes and behaviours (Healey, Bradley, \& Mukherjee, 2004), they are considered to have a strong influence on the types of needs consumers attempt to satisfy through their purchase and consumption behaviour (Tse, Belk, \& Zhou, 1989). Consumers from individualist and collectivist backgrounds develop different types of needs, which are reflected in the way they prioritise the product attributes which influence their buying behaviour (Gregory \& Munch, 1996). As a consequence, preferences for product attributes such as brand or quality across these two cultural groups may not be the same (Vinson, 1997). For example, in individualist cultures, consumers may prefer particular brands or products because those products provide expected functional benefits. Individualist consumers are not really worried about social status or prestige when they make purchasing decisions; they are more likely to focus on the performance of the product. By comparison, in collectivist cultures, consumers may prefer particular brands/products because those products can be used for symbolic purposes which are important within their culture. Collectivist consumers may purchase products that represent status, or that reassert their similarity to members of their reference group, while individualist consumers may purchase products that differentiate them from referent others (Aaker \& Maheswaren, 1997). In terms of automobile purchases, individualist consumers are likely to choose power and better performance over prestige or brand, whereas collectivist consumers may choose high-priced automobiles due to the associated status and prestige element (Wong \& Ahuvia, 1998). In addition, consumers may even draw on cultural values when searching/collecting information with regard to high involvement product purchases.

In collectivist cultures, it is expected that one will involve family and friends in the information search process (Doran, 2002). For example, in the situation of buying an automobile, consumers from collectivist cultures may seek the opinions of others regarding what information to collect and which types of sources are valuable to use. They are likely to first consult with their colleagues, friends and families, and to consider their advice or opinions before collecting information. They may also consider advice from friends and family in terms of which information sources are likely to be reliable such as magazines, word of mouth, spending time with dealers and test driving, to complete the information search process. As a whole, consumers from collectivist cultures may look for social approval from others, especially for highly visible or high involvement purchase like automobiles (Wong \& Ahuvia, 1998).

In contrast, since individualism is mainly reflected in being independent from others and being in control of one's surrounding environment, consumers from individualist cultures may be less likely to rely on others for example family members, peers and social groups in their purchase decisions. Individualist consumers rely on internal knowledge based on their personal experience, and seek out new experiences to expand upon that knowledge (Doran, 2002). They are less likely to rely on other people's opinions. For example, in terms of automobile purchases, they may spend a large amount of time looking at websites or speak to several dealers and test-drive several cars to extend their internal knowledge through their own personal experience. They are likely to utilise a much greater variety of patterns of information source rather than relying on friends and family. Friends and family might make suggestions, but decisions are made individually. To be more specific, the final decision might involve consultation with friends or family, but the purchaser usually feels that the decision is their own (Green, Deschamps, \& Paez, 2005). These variations in consumer information preferences might be utilised in marketing communication to create a more effective message when targeting consumers from these two different cultural backgrounds.

In summary, researchers, together with marketing practitioners, need to acknowledge cultural differences in order to better understand the consumer behaviour of individualist and collectivist consumers. Marketers also need to develop their strategies in terms of consumers' product involvement, for example, high and low (Mittal, 1995). Consumers' purchasing behaviour for high involvement purchase situations such as automobiles is 
different from low involvement purchase situations such as candy. High involvement purchases, such as automobiles, may be considered by consumers to reflect a particular image or social status (Wong \& Ahuvia, 1998 ) and this embedded symbolic meaning may influence consumers' purchasing decisions (Radder \& Huang, 2006). However, these symbolic meanings could differ according to consumers' cultural backgrounds (Luna and Gupta, 2001). Research has shown that consumers from different cultures vary in terms of the way they perceive brands (Radder \& Huang, 2006), for example, regarding the attributes they associate with those brands in their memories. Images and symbolic meanings attached to brands are shaped by a local society/culture in which the social values of a brand might vary greatly based on collective ideas about the brand (Jung \& Sung, 2005). For example, the symbolic meaning is likely to be different for individualist and collectivist consumers because of the differences in their cultural backgrounds, influencing high involvement decision-making for products such as automobiles. Despite the high level of interest in cross-cultural consumer behaviour research, there are very few or if any studies that have used automobiles as a high involvement purchase to identify the effect of cultural background, for example, individualism-collectivism on consumers' purchase decisions. As mentioned above, more research is needed in this area to investigate how cultural background affects in certain areas of consumers' decision-making process for high involvement purchases.

\section{Consumer Decision-Making Process for High Involvement Purchases}

In the context of making a high involvement purchase, consumers are usually aware of all the positives and negatives of each choice in terms of brand, quality, price and innovation (Mittal, 1995). Consumers attempt to forecast the outcome of each option in order to determine which is best for that particular situation so that they may make a reasoned decision. Consumers' decision-making for high involvement purchases such as automobiles consists of a sequential process involving problem recognition, information search, brand evaluation and selection, purchase and post-purchase (Punj, 1987). The influence of cultural dimensions, such as individualism-collectivism in several stages of the decision-making process, is presented and illustrated diagrammatically (see below, Figure 1). The aim of this section is to identify the influence that cultural background has upon individualist and collectivist automobile consumers in several stages of their consumer decision-making process.

\subsection{Automobile Purchase Decision: A Complex Problem Solving Situation}

Previous studies have stated that consumer decision-making for an automobile purchase is a complex problem solving process (Quester et al., 2007). This is reflected in automobile purchase situations. These situations are likely to be characterised by (a) active information seeking about various brands (Peterson \& Merino, 2003), (b) major comparison of product attributes (Radder \& Huang, 2006), (c) special preferences for a particular brand, such as brand loyalty (Dholakia, 2001) and (d) choices that are likely to be made with a high degree of awareness (Greenleaf \& Lehmann, 2005). For example, consumers usually require knowledge and preparation, such as an extensive information search, to learn about the product, and enough time to process and evaluate the available information so as to reach an appropriate automobile purchase decision (Bosnjak \& Rudolph, 2010).

Several models of consumer decision-making processes have been used in marketing research (see, for example, Nicosia model 1966; Howard-Sheth 1969; Engel et al., 1995; Sheth, Mittal, \& Newman, 1999; Neal, Quester, \& Hawkins, 2000). However, this study has adapted the model of Neal et al., (2000) to identify the cultural influences for automobile decision-making process (see below, Figure 1). 


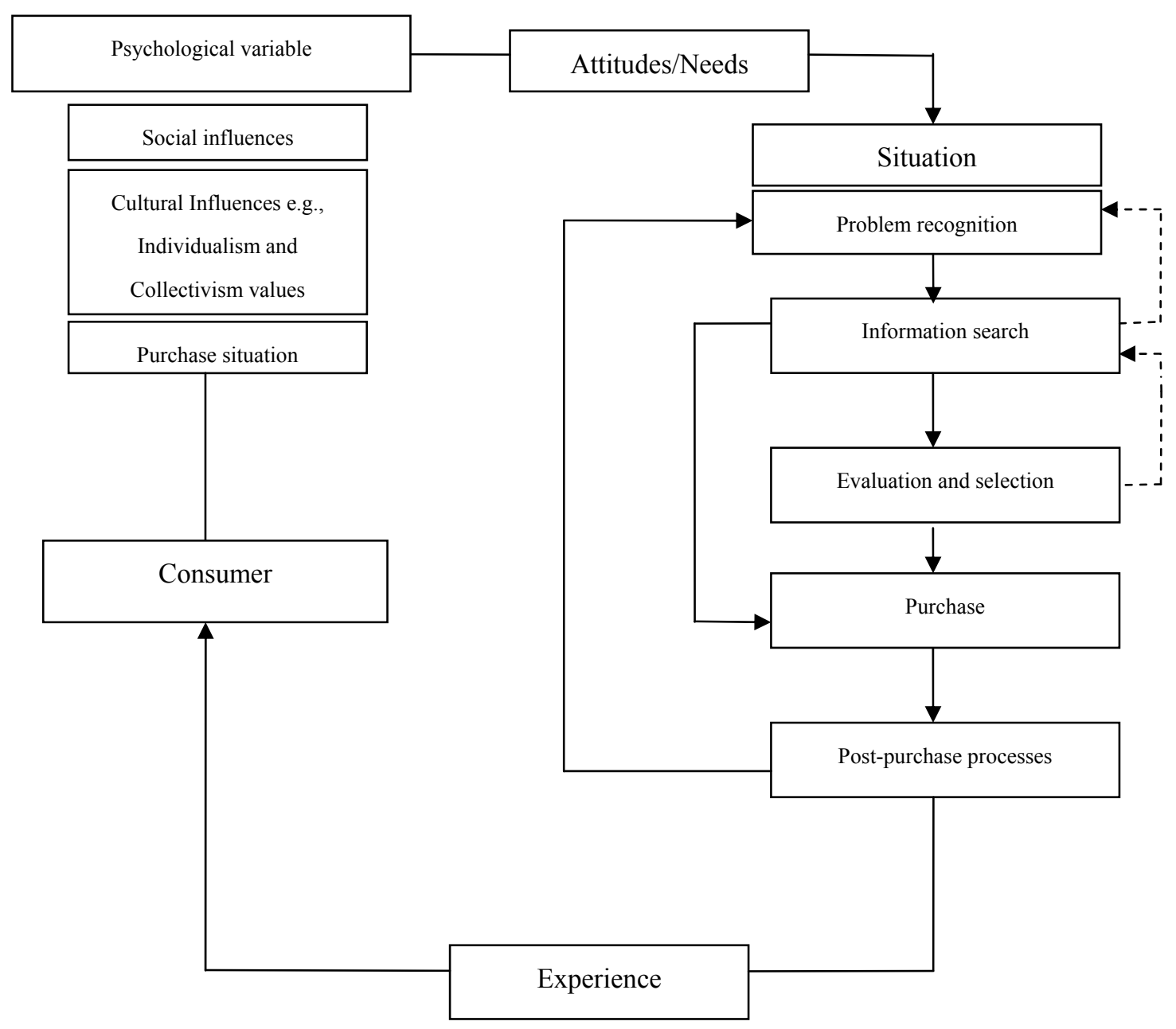

Source: adapted from Neal, Quester \& Hawkins (2000)

Figure 1. Consumer decision-making process model

\subsection{Neal, Quester and Hawkins (2000) Model}

Neal et al., (2000) model has been used in previous studies regarding the decision-making process in high involvement purchases (Okumus, Okumus, \& McKercher, 2007). This model was found to be effective due to its thorough five-stage (problem recognition, information search, evaluation and selection, purchase and post-purchase) explanation of the high involvement decision-making process (Quester et al., 2007). Moreover, the model illustrates that psychological variables, such as society and culture, are likely to have certain influences on consumers' attitudes and needs when they make decisions to purchase (Anurit, Newman, \& Chansarkar, 1998). The existence of a cultural influence factor in the model makes it an effective cross-cultural behaviour study tool, especially in the comparison between East and West (Okumus et al., 2007). The model of the consumer decision-making process shown in Figure 1 is described below within the context of automobile purchases. The following discussion is based on the shaded areas (see figure 1) of cultural influence, information search, evaluation and selection and purchase situation. 


\section{Hypotheses Development: Cultural Influences and Automobile Purchase Situation}

Consumer decision-making processes include the main aspects of information search, evaluation and selection and purchase behaviour (Grewal, Cline, \& Davies, 2003). This section looks at how these stages are related to the situation of automobile purchase and how cultural dimensions such as individualism and collectivism influence consumer decision-making within these three stages of the Neal et al., (2000) model.

\subsection{Information Search}

The information search involves an active search for information that is appropriate to the decision being made. The information search can be divided into the categories of internal and external, and both of these types of search are utilised by consumers for automobile purchases (Peterson \& Merino, 2003). The internal information search is memory-based and relies on the consumer's experience with the product, based on their previous information search activity (Sheth et al., 1999). An external or active information search is concerned with obtaining new information to assist in the making of the purchase decision, because the consumer feels that he/she does not have enough existing information with which to make an informed choice (Schmidt \& Spreng, 1996).

In addition, it is also important to mention that cultural dimensions, such as individualism and collectivism, may influence the pattern of information searches individual consumers are likely to follow (Piron, 2000). For example, collectivist consumers' information searches are likely to focus on friends, family and reference groups as sources of information. In contrast, individualist consumers are less likely to rely on the opinion of others. They are more likely to rely on information they have collected by themselves such as relying a great deal on internet and dealer (Doran, 2002).

Despite the influence that cultural background has in consumer information searches, many previous studies seem to have ignored this aspect (de Mooij, 2004). For example, Bloch \& Richins (1986) looked at a variety of potential determinants, motives and outcomes of both pre-purchase behaviour and the ongoing search, such as income and occupation, but did not look at any cultural differences in the information search (Doran, 2002).

However, there are some basic differences between individualist and collectivist consumers' information searches and usage which could be considered because those differences may be the reason for consumers' variation in product preferences (Doran, 2002). In terms of collecting information for automobile purchases, individualists may speak to more dealers or even test-drive several cars to extend their internal knowledge through their personal experience. In contrast, collectivists may speak to fewer dealers and are likely to rely more on the opinions of their friends and family. These different patterns of information searches may be the reason for consumers from different cultural groups choosing different brands of automobiles (Schmidt \& Spreng, 1996).

$H_{1 a}$ : There is a significant relationship between cultural background and the number of family members and friends involved in the automobile purchasing decision. Collectivist consumers involve more family members/friends than individualist consumers.

$H_{l b}$ : Collectivist consumers rate dealers as 'less important' source of information than individualist consumers in relation to automobile purchases.

\section{$H_{1 c}$ : Individualist consumers rely on internet as the most important source of information.}

\subsection{Evaluation and Selection}

Once the consumer has gathered the appropriate information, he/she is likely to assess the automobiles based on a range of evaluative criteria. The evaluation and selection stage is one of the most complex aspects of the decision-making process because of the wide variety of criteria (Bauer, Sauer, \& Becker, 2006). Evaluative criteria may vary according to product type (Mittal, 1995). Evaluative criteria for high involvement products or automobile purchases are the various features that consumers consider such as brand (Lockshin, Spawton, \& Mcintosh, 1997), price (Lichtenstein, Block, \& Black, 1988), quality (Prendergast \& Wong, 2003), brand loyalty (Bloemer \& Kasper, 2003), prestige (Vigneron \& Johnson, 1999) and innovation (Raju, 1980). Consumers' evaluation and selection processes may be the result of their emotional desires, which drive consumers to select products that fulfil specific and particular needs (Tsang \& Prendergast, 2009).

Consumers need, can be a result how society portrays values in consumers mind. Consumers in different country/culture are expected to be different in terms of the way they perceive international brands, e.g. attributes they associate with those brands in their memories. It is because images and symbolic meanings attached to brands are shaped by a local society/culture where economic and social values of a brand might vary greatly based on collective ideas about the brand (Jung \& Sung, 2005). For example, collectivist societies have a 
tendency to appreciate imported brands more than their own products/brands (Watson \& Wright, 2000). English tea, French perfume, German cars, Chinese silk, and Japanese electronics are their interests (Triandis, 1995) because they are expensive and stylish. Thus, they purchase expensive brands as a means of earning high social status (Dhar, 2007). Driving an imported car in some collectivist countries creates an image of prestige and is a symbol of high status. Collectivists may purchase a car not just to satisfy themselves but society as a whole. In an early study, Nagashima (1970) noted the fact that wealthy people in Japan bought German cars, as these were associated with high social recognition and status.

However, imported and popular brands are used to convey different meanings to individualist consumers. Brands generally help individualist consumers to reduce time spent on decision-making as the attributes associated with the brands are already familiar (Manari et al., 2001). This also reduces the risk involved in purchase decisions for individualist consumers. For example, brands like Volvo convey meanings of safety, and brands like Holden and Ford convey meanings relating to performance. In individualist cultures brands may be chosen as a risk reduction/minimizing strategy such that certain brands are associated with particular attributes and are therefore associated with less risk.

$\mathrm{H}_{2}$ : There is a significant relationship between cultural background and brand ratings. Collectivist consumers perceive European brands, for example, BMW, Mercedes and Volvo, to be superior to Ford, Holden, and Toyota.

\subsection{Purchase}

The purchase stage, in terms of buying automobiles, is the culmination of the decision-making process (Tsang \& Prenedergast, 2009). Having completed the information search and fulfilled the evaluation and selection criteria, consumers usually purchase the automobile in a transaction involving giving money to acquire the rights to the product (Yoo \& Donthu, 2002). Although culture is an important influence in the stages leading up to purchase, it has little bearing in the final transaction (Kim, Forsythe, Gu, \& Moon, 2002).

However, consumers may choose particular products/brands not only because these products provide the functional or performance benefits expected, but also because products can be used to express consumers' cultural backgrounds/values, personality, social status or affiliation (symbolic purposes). Consumer needs to be fulfilled through consumption of particular products or brands, however, vary considerably with the socio-economic and cultural differences among consumer markets. Consumers' product choice and preference for a particular product or brand are generally affected by very complex social influences (Kim et al., 2002). For example, collectivist consumers are prestige conscious and, therefore, they tend to focus more on perceived prestige in their purchase decisions. They are highly likely to choose products with apparent prestige, even when they are more expensive than other options.

\section{$H_{3}$ : Collectivist consumers buy more expensive automobiles than individualist consumers.}

\section{Research Methodology}

\subsection{Research Design and Method}

The research uses quantitative methods for example self-administered questionnaires. The sampling frame is individualist (i.e. Australian-born) and collectivist (i.e. Asian-born) who have purchased an automobile in the past 12 months. This sampling frame was selected on the basis that participants needed to be able to answer questions about their consumer behaviour in relation to purchasing an automobile; 12 months was expected to be a reasonable time frame for recalling purchase behaviour (Park \& Kim, 2003). The sampling technique was purposive sampling; the researcher specified the characteristics of the population of interest (individualist and collectivist consumers who had purchased a car within the last 12 months) and then located individuals who matched the needed characteristics. The researcher then located 100 people per cultural grouping (e.g. individualism and collectivism) who met the inclusion criteria and were willing to participate and included them in the research study. Participants were recruited via 12 dealerships in Melbourne. To improve response rates, participants were provided with reply paid envelopes to return their completion questionnaires. Participants consisted of 211 men (46.5\%) and women (53.5\%) from individualist (Australian-born) or collectivist (Asian-born) backgrounds that had purchased a car within the last 12 months. Out of 422 surveys that were distributed for this study, 222 were returned, of which 11 incomplete surveys were discarded. These ten incomplete surveys were discarded because more than $10 \%$ of the results were missing values. For thorough estimates and analyses, only those surveys that were filled out correctly and completely were used for this study ( $49 \%$ of the total distribution). 


\subsection{Measurement}

The study measures were selected for the purpose of examining whether there are cross-cultural differences in various stages of consumer decision-making process. The questionnaire was divided into the following four sections:

\subsubsection{Demographic Questions}

Participants were asked to provide information about their age, citizenship, country of birth (Asian-born participants only), gender, education, first spoken language, household income, length of time in Australia (Asian-born participants only), marital status, number of children under 18, and parents' country of birth.

\subsubsection{Cultural Values Scale (CVS)}

The Cultural Values Scale (CVS; Singelis et al., 1995) is an established scale consisting of 32 statements that measure individualist and collectivist cultural values. Participants rated their agreement/disagreement with each statement on a 7-point scale ranging from "strongly disagree" (1) to "strongly agree" (7). A sample item is, "My happiness depends very much on the happiness of those around me". The CVS consists of 2 subscales and each has 16 items; (a) Individualism and (b) Collectivism. The reason to use cultural values scale is to measure/confirm the cultural values among the respondents from two different cultural backgrounds, which means if the respondents are aligned with the particular group (i.e. Asian with collectivism and Australian with individualism).

\subsubsection{Questions on Driving History}

This set of questions was asked of participants to find out the price of the car, make of car or the brand participants have purchased to compare between individualist and collectivist consumers' automobile purchase behaviour. Participants were also asked how long ago they purchased their car because for the purpose of this study the respondents were only included if they purchased no longer than twelve months ago. Response format was a mixture of 'fill in the blank' and 'tick the most appropriate alternative'.

\subsubsection{External Influences on Consumer Decision-Making}

Participants supplied information about (potential) external influences on consumer decision making when purchasing a car. These factors included perceived importance of dealers, number of dealers consulted, time spent with dealers, number of cars test driven, time spent on research, perceived importance of family and friends, and number of family/friends consulted. The response format for these questions was 'tick the most appropriate alternative'. In addition, participants rated the relative importance of different information sources (e.g., dealers, internet, magazines, TV ads, word of mouth) on a seven-point scale ranging from 1 = "very unimportant" to 7 = "very important").

\section{Results}

\subsection{Individualist and Collectivist Value Differences}

Table 1 shows the means and standard deviations for individualism and collectivism within each cultural group.

Table 1. Individualism and collectivism by cultural group

\begin{tabular}{ccccc}
\hline & \multicolumn{2}{c}{ Australian-born } & \multicolumn{2}{c}{ Asian-born } \\
\hline $\begin{array}{c}\text { Cultural } \\
\text { Background }\end{array}$ & Mean & SD & Mean & SD \\
Individualism & 4.40 & .76 & 4.39 & .66 \\
Collectivism & 4.18 & .67 & 4.93 & .83 \\
\hline
\end{tabular}

An independent samples t-test was performed, with country of birth (Australia versus Asia) as the independent variable and individualism and collectivism as the dependent variables. Results indicated that Asians scored significantly higher than Australians on collectivism, $\mathrm{t}(192.042)=-7.045, \mathrm{p}<.001$ (mean difference $=.766$ ). However, there was no difference for individualism, $\mathrm{t}(200)=.14, \mathrm{p}=.89$. 
To test for differences in the demographic characteristics of the two groups (due to sampling), chi-square tests were performed with country of birth as the independent variable and age, gender, education, marital status, income and number of years driving as the dependent variables (Bonferroni adjustment was used to correct for Type 1 error). Results revealed that Australian-born and Asian-born consumers differed on the following demographic variables: age $\chi(5)=25.81, \mathrm{p}<.001$, education $\chi(5)=36.61, \mathrm{p}<.001$ and $\operatorname{sex} \chi(6)=26.37, \mathrm{p}$ $<.001$. Demographic variables that significantly differed between the groups and were correlated with the consumer decision-making styles were subsequently controlled (included as covariates) in the hypotheses testing analyses.

\subsection{Hypothesis Testing Analyses}

\subsubsection{Hypothesis 1}

$\mathrm{H}_{1 \mathrm{a}}$ : Results showed a significant differences between individualist and collectivist consumer groups in relation to number of family/friends are involved in decision-making, $\mathrm{t}(199)=-3.77, p<.001$ (mean difference $=.0 .54$ ), with collectivist participants (Asian-born) scored higher than individualist (Australian-born) participants. As predicted collectivist participants involved a large/more number of family and friends in their decision-making than individualist consumers. Therefore, $\mathrm{H}_{1 \mathrm{a}}$ was supported.

$\mathrm{H}_{1 \mathrm{~b}}$ : A comparison of the 'importance of dealers' between the two groups found no significant differences; $\mathrm{t}$ $(199)=.759, p>.05$. Therefore, $\mathrm{H}_{1 \mathrm{~b}}$ was not supported.

$\mathrm{H}_{1 \mathrm{c}}$ : Results showed a significant differences between these two consumer groups for important source of information, $\mathrm{t}(199)=3.61, p<.001$ (mean difference $=.0 .59$ ), with individualist participants scored higher than collectivist participants. As predicted, individualist participants rely on internet as the most important source of information. Therefore, $\mathrm{H}_{1 \mathrm{c}}$ was supported.

\subsubsection{Hypothesis 2}

A comparison of perceived brand ratings between the two groups indicated that collectivist participants rated the brand quality of BMW $\mathrm{t}(197.38)=2.32, p<.005$ (mean difference $=.316)$ and Mercedes $\mathrm{t}(200)=2.69, p$ $<.005$ (mean difference $=.363$ ) more highly than did individualist participants.

Individualist participants rated Ford $\mathrm{t}(200)=2.32, p<.005$ (mean difference $=.313$ ) more highly than collectivist participants. Therefore, $\mathrm{H}_{2}$ was supported.

However, there were no other significant differences in brand quality ratings between the groups: Volvo $\mathrm{t}(200)$ $=.40, p>.05$; Holden $\mathrm{t}(180.74)=1.16, p>.05$; and Toyota $\mathrm{t}(200)=1.10, p>.05$.

\subsubsection{Hypothesis 3}

There was no significant difference between the groups in terms of buying expensive automobiles; $\mathrm{t}(199)=$ $-.979, p>.05$. Therefore, $\mathrm{H}_{3}$ was not supported.

\section{Discussion and Managerial Implications}

The research investigates how cultural background such as individualism and collectivism affects in certain areas of consumers' decision-making process for high involvement purchases. The results of this study showed that hypotheses $\mathrm{H}_{1 \mathrm{a}}, \mathrm{H}_{1 \mathrm{c}}$ and $\mathrm{H}_{2}$ were supported.

Results revealed that Asian-born consumers rely heavily on friends and family as the most important source of information. Other sources of information Asian-born consumers' use include television advertisements, newspapers, billboards and magazines (Doran, 2002). Therefore, marketers need to be aware of this situation and provide similar, or even the same, types of information/messages by using these above-mentioned sources to communicate with Asian-born consumers, so that they do not become confused. The information/messages could include less information on mechanical and innovative features of the automobiles. It is not that Asian-born consumers do not want to know about these features, but the first impression they are likely to prefer is that which emphasises the prestige of the automobile.

The research also revealed that Asian-born consumers are brand conscious and perceive European brands, for example, BMW and Mercedes, to be superior. Asian-born consumers may be looking for social approval from others, especially when making highly visible or high involvement purchases such as automobiles. Therefore, companies need to have this in mind and try to promote their automobiles for Asian-born consumers with strategies that highlight the significance of status and prestige. Marketing messages/information for Asian-born consumers could focus heavily on the social approval and high prestige which consumers can gain by purchasing automobiles. In relation to communicating with Asian-born consumers, automobile companies need 
to use Dealers as an important source of information. Dealers could be trained (or from the same cultural background, if possible) to spend time explaining product features and benefits in full with Asian-born consumers and their friends and family members whom they are likely to bring along before making the final decision to purchase. This could be a successful approach, if followed when developing strategies for Asian-born consumers.

The research showed that Australian-born consumers use internet as most preferred information source. Therefore, in terms of communicating with Australian-born consumers, marketers might utilise the internet as a promotion or communication technique for distributing automobile information and to emphasise the cutting edge, innovative aspects of their products.

Finally, Given that these differences cannot be explained in terms of variation between the two groups on individualism and collectivism, an explanation might be found in other sources of systematic variation between the two groups. For example, variation in language, religion, spending power, or attitudes/beliefs could account for the present findings (Kang \& Kim, 1998). Research showed that Asian-born consumers prefer a nonverbal, literal message which may explain the reason their evaluation and selection criteria is different from Australian-born consumers and identification of this criterion is crucial for automobile marketers. However, these are avenues for future research.

\section{Limitations}

This research could not conclude that the differences between individualist and collectivist consumers are unique to high involvement purchases. Future research might compare consumer's purchase behaviour for several situations within the same study, for example, low and high involvement purchases. In addition, an approach involving high and low involvement purchase decisions would further enhance both theoretical and practical understanding of shopping behaviour in different cultures (Blodgett, Bakir, \& Bashir, 2008). In this research, participants were asked to describe/rate consumers' behavioural approach which was taken in relation to automobile purchases retrospectively. Respondents had purchased a car within the last twelve months. However, twelve months is quite a long lag for respondents to remember every detail about their purchase decisions. Therefore, future research should follow consumers during the actual purchase process, in real time, to deliver more accurate results.

In this research, there were no differences found in individualism observed between Australian-born and Asian-born respondents, however there were differences in collectivism observed between Australian-born and Asian-born respondents, such that Asian-born respondents scored higher on collectivism. While there were some differences in the consumer behaviour of Australian-born versus Asian-born respondents, these differences were not accounted for by the cultural value dimensions of individualism and collectivism. Future research could involve other cultural dimensions, such as masculine-feminine, power distance and long-term and short-term orientations, to distinguish their influences in consumer decision-making styles for automobile purchases.

The research did not highlight the possible cultural differences in post purchase behavioural stge. Given that automobile is a high involvement purchase situation and therefore post purchase behaviour is an important criteria for consumers to choose their preferable brands. Future research should consider this stage so to identify the reasoned decision made by consumers from these two different cultural groups.

\section{Conclusions}

Marketing communication messages may influence consumers' purchase decisions through recognising the cultural differences that have discussed previously. Since Asian-born consumers generally give preference to group goals over individual goals or interests, it may be more effective for marketers to communicate with them at a group-level rather than at an individual level. For instance, marketing messages could be developed more in terms of family and social/cultural values which emphasise group-consensus appeals, family ties and family security. Appeals such as "working together" and "it is so good that you want to share it with others" are particularly popular in these societies. On the other hand, for Australian-born consumers messages might be developed more in terms of functional or performance benefits. 


\section{References}

Aaker, J.L., \& Maheswaren, D. (1997). The Effect of Cultural Orientation on Persuasion. Journal of Consumer Research, 24, 315-328. http://dx.doi.org/10.1086/209513

Anurit, J., Newman, K., \& Chansarker, B. (2008). Consumer Behaviour of Luxury Automobiles: A Comparative Study between Thai and UK Customers Perceptions. Journal of Consumer Marketing Management, 14, 749-763.

Arnold, E. J., \& Thompson, C. J. (2005). Consumer Culture Theory (CCT): Twenty Years of Research. Journal of Consumer Research, 31, 193-219.

Barney, J. B. (1986). Organizational Culture: Can It Be a Source of Sustained Competitive Advantage? The Academy of Management Review, 11, 656-665.

Bauer, H. S., Sauer, N. E., \& Becker, C. (2006). Investigating the Relationship between Product Involvement and Consumer Decision Making Styles. Journal of Consumer Behaviour, 5, 342-354. http://dx.doi.org/10.1002/cb.185

Bloch, P. H., \& Richins, M. L. (1983). A Theoretical Model for the Study of Product Importance Perceptions. Journal of Marketing, 47, 69-81. http://dx.doi.org/10.2307/1251198

Blodget, J., Bakir, A., \& Rose, G. (2008). A Test of the Validity of Hofstede's Cultural Framework. Journal of Consumer Marketing, 25, 339-349. http://dx.doi.org/10.1108/07363760810902477

Bloemer, J. M., \& Kasper, H. D. P. (2003). The Complex Relationship between Consumer Satisfaction and Brand Loyalty. Journal of Economic Psychology, 16, 311-329. hattp://dx.doi.org/10.1016/0167-4870(95)00007-B

Bond, M. H., Al Au, K. L., Tong, K., Carrrasquel, S. R., Murakami, F., Yamaguchi, S., \& Singelis, T. M. (2004). Culture-level Dimensions of Social Axioms and their Correlates Across 41 Cultures. Journal of Cross-Cultural Psychology, 35, 548-570. http://dx.doi.org/10.1177/0022022104268388

Bosnjak, M. (2010). Negative Symbolic Aspects in Destination Branding: Exploring the Role of the 'Undesired Self' on Web-based Vacation Information Search Intentions among Potential first-time Visitors. Journal of Vacation Marketing, 16, 323-330. http://dx.doi.org/10.1177/1356766710380885

Cleveland, M., \& Chang, W. (2009). Migration and Materialism: The Roles of Ethnic Identity, Religiosity, and Generation. Journal of Business Research, 6, 963-971. http://dx.doi.org/10.1016/j.jbusres.2008.05.022

De Mooij, M. (2004). Consumer Behaviour and Culture: Consequences for Global Marketing and Advertising. Sage Publications, Thousand Oaks, CA.

De Mooij, M. (2010). Global Marketing and Advertising: Understanding Cultural Paradoxes (3rd ed.). Sage Publications Asia-Pacific, Singapore.

De Mooij, M., \& Hofstede, G. (2002). Convergence and Divergence in Consumer Behavior: Implications for International Retailing. Journal of Retailing, 78, 61-69. http://dx.doi.org/10.1016/S0022-4359(01)00067-7

Dhar, M. (2007). Brand Management 101-101 Lessons from Real World Marketing. John Wiley \& Sons (Asia) Pte Ltd, Singapore.

Dholakia, U. M. (2001). A Motivational Process Model of Product Involvement and Consumer Risk Perception. European. Journal of Marketing, 35, 1340-1362. http://dx.doi.org/10.1108/EUM0000000006479

Doran, K. B. (2002). Lessons Learnt in Cross-Cultural Research of Chinese and North American Consumers. Journal of Business Research, 55, 823-829. http://dx.doi.org/10.1016/S0148-2963(00)00222-8

Farhangmehr, M., \& Shoham, A. (2007). Hofstede's Dimensions of Culture in International Marketing Studies. Journal of Business Research, 60, 277-284. http://dx.doi.org/10.1016/j.jbusres.2006.10.018

Green, E. G. T., Deschamps, J. C., \& Paez, D. (2005). Variation of Individualism and Collectivism within and between 20 Centuries: A Typological Analysis. Journal of Cross-Cultural Psychology, 36, 321-339. http://dx.doi.org/10.1177/0022022104273654

Greenleaf, E., \& Lehmann, D. (2005). Reasons for Substantial Delay in Consumer Decision Making. Journal of Consumer Research, 22, 186-199. http://dx.doi.org/10.1086/209444

Gregory, G. D., \& Munch, J. M. (1997). Cultural Values in International Advertising: An Examination of Familial Norms and Roles in Mexico. Psychology \& Marketing, 14, 99-119. 
http://dx.doi.org/10.1002/(SICI)1520-6793(199703)14:2<99::AID-MAR1>3.0.CO;2-I

Grewal, R., Cline, T. W., \& Davies, A. (2003). Early-Entrant Advantage, Word-of-Mouth Communication, Brand Similarity, and the Consumer Decision Making Process. Journal of Consumer Psychology, 13, 187-197. http://dx.doi.org/10.1207/S15327663JCP1303_01

Healy, G., Bradly, H., \& Mukherjee, N. (2004). Individualism and Collectivism Revisited: A Study of Black and Minority Ethnic Women. Industrial Relations Journal, 35, 451-466. http://dx.doi.org/10.1111/j.1468-2338.2004.00326.x

Henry, W. A. (1976). Cultural Values Do Correlate with Consumer Behaviour. Journal of Marketing Research, 13, 121-127. http://dx.doi.org/10.2307/3150845

Hofstede, G. (1980). Culture's Consequences: International Differences in Work- Related Value. Sage Publications, Beverly Hills, CA.

Hofstede, G. (1983). National Cultures in Four Dimensions. International Studies of Management and Organisations, 13, 46-74.

Hofstede, G. (1984). Culture's Consequences: International Differences in Work-related Values. Sage Publications, Newbury Park, CA.

Hofstede, G. (2001). Culture's Consequences: Comparing Values Behaviours, Institutions and Organisations Across Nations. Sage Publications, London.

Jung, J., \& Sung, E. (2008). Consumer-Based Brand Equity: Comparisons among Americans and South Koreans in the USA and South Koreans in Korea. Journal of Fashion Marketing and Management, 12, 24-35. http://dx.doi.org/10.1108/13612020810857925

Kacen, J. J., \& Lee, J. A. (2002). The Influence of Culture on Consumer Impulsive Buying Behavior. Journal of Consumer Psychology, 12, 163-176. http://dx.doi.org/10.1207/S15327663JCP1202_08

Kang, J., \& Kim, Y. (1998). Ethnicity and Acculturation: influences on Asian American Consumers' Purchase Decision Making for Social Clothes. Journal of Advertising Research, 27, 91-117.

Kelley, P., \& Wendt, L. (2002). Symposium on Negligence. Chicago Kent Law Review, 77, 587-623.

Kim, J., Forsythe, S., Gu, Q., \& Moon, S.J. (2002). Cross-Cultural Consumer Values, Needs and Purchase Behaviour. Journal of Consumer Marketing, 19, 481-502. http://dx.doi.org/10.1108/07363760210444869

Latvin, S. W., \& Kar, G. H. (2007). Individualism/Collectivism as A Moderating Factor to the Self-image Congruity Concept. Journal of Vacation Marketing, 10, 23-32. http://dx.doi.org/10.1177/135676670301000103

Leo, C., Bennett, R., \& Hartel, E. J. (2005). Cross Cultural Differences in Consumer Decision Making Styles. Cross Cultural Management, 12, 32-61. http://dx.doi.org/10.1108/13527600510798060

Lichtenstein, D. R., Block, P. H., \& Black, W. C. (1988). Correlates of Price Acceptability. Journal of Consumer Research, 15, 243-252. http://dx.doi.org/10.1086/209161

Liu, R. R., \& Mcclure, P. (2001). Recognizing Cross-Cultural Differences in Consumer Complaint Behaviour and Intentions: An Empirical Examination. Journal of Consumer Marketing, 18, 54-75. http://dx.doi.org/10.1108/07363760110365813

Lockshin, L. S., Spawton, A. L., \& Macintosh, G. (1997). Using Product, Brand, and Purchasing Involvement for Retail Segmentation. Journal of Retailing and Consumer Services, 4, 171-183. http://dx.doi.org/10.1016/S0969-6989(96)00048-3

Luna, G., \& Gupta, S. F. (2001). An Integrative Framework for Cross-Cultural Consumer Behaviour. International Marketing Review, 18, 45-69. http://dx.doi.org/10.1108/02651330110381998

Manrai, L. A., \& Manrai, A. K. (1996). Global Perspective in Cross-cultural and Cross National Consumer Research. International Business Press, Binghamton, NY.

Manrai, L. A., Lascu, D., Manrai, A. K., \& Babb, H. W. (2001). A Cross-Cultural Comparison of Style in Eastern European Emerging Markets. International Marketing Review, 18, 270-285. http://dx.doi.org/10.1108/02651330110396479

McSweeny, B. (2002). Hofstede's Model of National Cultural Differences and their Consequences: A Triumph of Faith-A Failure of Analysis. Human Relations, 55, 89-118. 
Mittal, B. (1995). A Comparative Analysis of Four Scales of Consumer Involvement. Psychology \& Marketing, 12, 663-682. http://dx.doi.org/10.1002/mar.4220120708

Mourali, M., Laroche, M., \& Pons, F. (2005). Individualistic Orientation and Consumer Susceptibility to Interpersonal Influence. Journal of Services Marketing, 19, 164-173. http://dx.doi.org/10.1108/08876040510596849

Nagashima, A. (1970). A Comparison of Japanese and U. S. Attitudes toward Foreign Products. Journal of Marketing, 34, 68-74. http://dx.doi.org/10.2307/1250298

Neal, C., Quester, P., \& Hawkins, D. (2000). Consumer Behaviour-Implications for Marketing Strategy. Irwin/McGraw-Hill, Sydney, NSW.

Okumus, B., Okumus, F., \& McKercher, B. (2007). Incorporating Local and International Cuisines in the Marketing of Tourism Destinations: The Cases of Hong Kong and Turkey. Tourism Management, 28, 253-261. http://dx.doi.org/10.1016/j.tourman.2005.12.020

Park, C., \& Kim, Y. (2003). Identifying Key Factors Affecting Consumer Purchase Behaviour in an Online Shopping Context. International Journal of Retail \& Distribution Management, 31, 16-29. http://dx.doi.org/10.1108/09590550310457818

Perterson, R. A., \& Merino, M. C. (2003). Consumer Information Search Behaviour and the Internet. Psychology \& Marketing, 20, 99-121. http://dx.doi.org/10.1002/mar.10062

Piron, F. (2000). Consumers' Perception of the Country-of-Origin Effect on Purchasing Intentions of (in) Conspicuous Products. Journal of Consumer Marketing, 17, 308-321. http://dx.doi.org/10.1108/07363760010335330

Prendergast, G., \& Wong, C. (2008). Parental Influence on the Purchase of Luxury Brands of Infant Apparel: An Exploratory Study in Hong Kong. Journal of Consumer Marketing, 20, 157-169. http://dx.doi.org/10.1108/07363760310464613

Punj, G. (1987). Presearch Decision Making in Consumer Durable Purchases. Journal of Consumer Marketing, 4, 71-82. http://dx.doi.org/10.1108/eb008191

Quester, P., Neal, C., \& Hawkins, D. (2007). Consumer Behaviour Implication for Marketing Strategy (5th ed.). McGraw-Hill Irwin, North Ryde, NSW.

Radder, L., \& Huang, W. (2008). High involvement and Low involvement Products: A Comparison of Brand Awareness among Students at a South African University. Journal of Fashion Marketing and Management, 12, 232-243. http://dx.doi.org/10.1108/13612020810874908

Raju, P. S. (1980). Optimum Stimulation Level: Its Relationship to Personality, Demographics and Exploratory Behaviour. Journal of Consumer Research, 7, 272-282. http://dx.doi.org/10.1086/208815

Schmidt, J. B., \& Spreng, R. A. (2006). A Proposed Model of External Consumer Information Search. Journal of the Academy of Marketing Science, 24, 246-256. http://dx.doi.org/10.1177/0092070396243005

Sheth, J. N., Mittal, B., \& Newman, B. (1999). Customer Behaviour: Consumer Behaviour and Beyond. Dryden Press, Fort Worth, TX. http://dx.doi.org/10.1177/106939719502900302

Singelis, T. M., Triandis, H. C., Bhawuk, D. P. S., \& Gelfand, M. J. (1995). Horizontal and Vertical Dimensions of Individualism and Collectivism: A Theoretical and Measurement Refinement. Cross-cultural Research, 29, 240-275.

Steenkamp, J. E. M., Hofstede, F., \& Wedel, M. (1999). A Cross-National Investigation into the Individual and National Cultural Antecedents of Consumer Innovativeness. Journal of Consumer Marketing, 63, 55-69.

Triandis, H. C. (1995). Self Description and Cultural Values Scale; Individualism and Collectivism. Westview Press, Boulder, CO.

Tsang, A. S. L., \& Prendergast, G. (2009). Does Culture Affect Evaluation Expressions?: A Cross-Cultural Analysis of Chinese and American Computer Game Reviews. European Journal of Marketing, 43, 686-707. http://dx.doi.org/10.1108/03090560910947007

Tse, D. K., Belk, R.W., \& Zhou, N. (1989). Becoming A Consumer Society: A Longitudinal and Cross-Cultural Content Analysis of Print Advertisements from Hong Kong, People's Republic of China, and Taiwan. Journal of Consumer Research, 15, 457-472. http://dx.doi.org/10.1086/209185

Venkatesh, A. (1995). Ethnocentrism: A New Paradigm to Study Cultural and Cross-Cultural Consumer 
Behaviour. In JA Costa \& GJ Bamossy (eds). Marketing in a Multicultural World, Sage Publications, Thousand Oaks, CA, pp. 27-63.

Vigneron, F., \& Johnson, F. W. (1999). A Review and a Conceptual Framework of Prestige-Seeking Consumer Behaviour. Academy of Marketing Science Review, 1, 1-15.

Vinson, D. E. (1997). The Role of Personal Values In Marketing and Consumer Behaviour. Journal of Marketing, 41, 44-50. http://dx.doi.org/10.2307/1250633

Watson, J. J., \& Wright, K. (2000). Consumer Ethnocentrism and Attitudes Toward Domestic and Foreign Products. European Journal of Marketing, 34, 1149-1166. http://dx.doi.org/10.1108/03090560010342520

Wong, N. Y., \& Ahuvia, A. C. (1998). Personal Taste and Family Face: Luxury Consumption In Confucian and Western Societies. Psychology \& $\quad$ Marketing, $423-444$. http://dx.doi.org/10.1002/(SICI)1520-6793(199808)15:5<423::AID-MAR2>3.0.CO;2-9

Yoo, B., \& Donthu, N. (2002). Testing Cross-Cultural Invariance of the Brand Equity Creation Process. Journal of Product \& Brand Management, 11, 380-398. http://dx.doi.org/10.1108/10610420210445505 